\title{
Frequency of Cardiovascular Risk Factors in Systemic Lupus Erythematosus: A Case-Control Study in a Department of Internal Medicine in Sub-Saharan Africa
}

\author{
Maïmouna Sow ${ }^{1 *}$, Baïdy Sy Kane ${ }^{1}$, Abdourahmane Sambaㄹ, Awa Cheikh Ndao, \\ Nafissatou Diagne ${ }^{1}$, Boundia Djiba ${ }^{1}$, Mouhamed Dieng ${ }^{1}$, Atoumane Faye ${ }^{1}$, Abdoulaye Pouye ${ }^{1}$ \\ ${ }^{1}$ Internal Medicine Department, Aristide Le Dantec Teaching Hospital, Dakar, Senegal \\ ${ }^{2}$ Biochemistry Department, Aristide Le Dantec Teaching Hospital, Dakar, Senegal \\ Email: *mouna89Sow@hotmail.fr
}

How to cite this paper: Sow, M., Kane, B.S., Samba, A., Ndao, A.C., Diagne, N., Djiba, B., Dieng, M., Faye, A. and Pouye, A. (2020) Frequency of Cardiovascular Risk Factors in Systemic Lupus Erythematosus: A Case-Control Study in a Department of Internal Medicine in Sub-Saharan Africa. Open Journal of Internal Medicine, 10, $1-12$.

https://doi.org/10.4236/ojim.2020.101001

Received: December 10, 2019

Accepted: January 5, 2020

Published: January 8, 2020

Copyright $\odot 2020$ by author(s) and Scientific Research Publishing Inc. This work is licensed under the Creative Commons Attribution International License (CC BY 4.0).

http://creativecommons.org/licenses/by/4.0/ (c) (i) Open Access

\begin{abstract}
Background: The morbidity and mortality of systemic lupus erythematosus are largely due to accelerated atherosclerosis. This is partly related to the high prevalence of traditional cardiovascular risk factors. The aim of our study was to determine the frequency of these factors in lupus patients compared to a control population in a department of internal medicine. Methods: We realized a case-control study in patients with systemic lupus erythematosus according to ACR criteria in 1997. Patients were matched by age and gender with controls subjects without autoimmune disease. We studied the frequency of traditional cardiovascular risk factors in both populations. The study was done in the department of internal medicine of Aristide Le Dantec teaching Hospital, in Senegal, during the period from August 2017 to December 2018. The statistical analysis was performed with SPSS 23.0 software and the level of significance was retained for a p-value $<0.05$. Results: We recruited 100 subjects including 50 patients and 50 controls. The mean age was $33.5 \pm 11.3$ years in cases and $33.3 \pm 11.3$ years in controls. Dyslipidemia was significantly associated with systemic lupus erythematosus $(p=0.009)$. Levels of triglycerides $(\mathrm{p}<0.001)$ and uricemia $(\mathrm{p}<0.001)$ were significantly higher in patients. The level of HDL cholesterol $(\mathrm{p}=0.028)$ was lower in cases. Thus, low HDL cholesterolemia $(\mathrm{p}=0.001)$, hypertriglyceridemia $(\mathrm{p}<$ $0.001)$, and hyperuricemia $(p=0.043)$ were more common in the cases. Renal failure was associated with systemic lupus erythematosus $(\mathrm{p}<0.001)$. Difference in LDL-cholesterol $(p=0.103)$, hypertension $(p=1)$ and metabolic syndrome $(p=1)$ between cases and controls was not significant. Obesity and overweight were predominant in controls $(p=0.028)$. Conclusion: Tradi-
\end{abstract}


tional cardiovascular risk factors including dyslipidemia and hyperuricemia were more common in patients. Similarly, renal failure was associated with lupus.

\section{Keywords}

Cardiovascular Risk Factors, Systemic Lupus Erythematosus, Sub-Saharan Africa

\section{Introduction}

Cardiovascular mortality is estimated between $10 \%$ and $20 \%$ of the overall mortality during systemic lupus erythematosus (SLE). Ischemic cardiovascular disease is currently a major cause of mortality after 5 years of progression of the pathology [1] [2]. More than a third of patients with SLE have subclinical atherosclerosis. Accelerated atherosclerosis and premature coronary heart disease are major causes of morbidity and mortality in patients with SLE [1]. Factors in SLE that appear to promote subclinical atherosclerosis include chronic inflammation, more frequency traditional risk factors, lupus duration, disease activity, renal impairment, and long-term corticosteroid therapy [1] [2]. A recent study suggests that during SLE, there is a decrease in HDL cholesterol and an elevation in LDL cholesterol, total cholesterol and triglycerides. HDL cholesterol is dysfunctional and acquires pro-inflammatory properties [2] [3]. Screening and early management of these risk factors could therefore improve the prognosis of these patients.

The prevalence of cardiovascular events in SLE also shows racial and ethnic variations. The risk of stroke is higher in black people [2].

This study contributes to provide data of cardiovascular risk factors associated with SLE in black African populations.

For this purpose, we aim to evaluate the frequency of traditional cardiovascular risk factors in a population of lupus patients compared to a control population.

\section{Patients and Methods}

This was a case-control study in the department of internal medicine, nephrology and dermatology of Aristide Le Dantec teaching Hospital, in Senegal. We compared lupus patients with controls subjects, regarding the frequency of cardiovascular risk factors. Matching was done by age and gender. We recruited consecutively consenting patients across the consultation and hospitalization sectors. The case evaluation was made during the period from August 2017 to December 2018.

Cases and controls

The diagnosis of SLE was based on the criteria of the 1997 ACR [4]. Patients with other chronic diseases or other autoimmune diseases were not included. The controls were subjects without SLE or other autoimmune diseases. They were matched by age and gender to cases. Patients and controls signed an informed consent form. The clinical research consultation was free, as were the 
complementary explorations.

\section{Data collection}

For each patient included, a data sheet containing sociodemographic, clinical, biological and therapeutic elements was designed. Sociodemographic data included age, gender and ethnicity. Antecedents included family history of cardiovascular disease, diabetes mellitus, hypertension or personal cardiovascular disease. Other factors as smoking, sedentary lifestyle, were assessed. Clinically, duration of lupus and delay of diagnosis were specified. Evaluation of the disease activity at the diagnosis and the evaluation was performed by the clinical SLEDAI (cSLEDAI). The taking of anthropometric constants i.e. blood pressure, weight, height, body mass index and waist circumference were done. The following biological data were collected: fasting blood glucose, urea, creatinine, total cholesterol, low-density lipoprotein cholesterol (LDL cholesterol), high-density lipoprotein cholesterol (HDL cholesterol), triglycerides and uricemia. The following therapeutic data were noted: the duration, daily and cumulative dose of corticosteroid therapy, the nature of the other treatments used.

\section{Definition of values}

Threshold values of the different parameters are defined in Table 1.

Table 1. The definition of the threshold value of the different parameters.

\begin{tabular}{|c|c|}
\hline Parameters & Definition \\
\hline Sedentary lifestyle & $\begin{array}{l}\text { less than } 150 \text { minutes of moderate activity per week or } 75 \text { minutes of } \\
\text { intense activity per week }\end{array}$ \\
\hline Obesity & criteria of the $\mathrm{WHO}^{*}[5]$ \\
\hline metabolic syndrome & definition of the International Diabetes Federation [6] \\
\hline diabetes mellitus & known diabetic patients \\
\hline HTA $^{*}$ & known hypertensive patients with or without treatment \\
\hline High $\mathrm{BP}^{*}$ & $\mathrm{SBP}^{*} \geq 140 \mathrm{mmHg}$ and $/$ or $\mathrm{DBP}^{*} \geq 90 \mathrm{mmHg}$ \\
\hline early CVD* & $\begin{array}{l}\text { stroke, acute coronary syndromes, and hypertension occurring before } \\
\text { the age of } 40 \text { years }\end{array}$ \\
\hline $\begin{array}{l}\text { Fasting blood glucose } \\
\text { abnormal }\end{array}$ & $>1.10 \mathrm{~g} / \mathrm{L}$ \\
\hline High plasma Urea & $>0.45 \mathrm{mg} / \mathrm{L}$ \\
\hline High plasma creatinine & $>13 \mathrm{mg} / \mathrm{L}$ \\
\hline High total cholesterol & $>2.8 \mathrm{~g} / \mathrm{l}$ \\
\hline Low $\mathrm{HDL}^{\star}$ cholesterol & $\leq 0.4 \mathrm{~g} / \mathrm{l}$ \\
\hline $\mathrm{LDL}^{*}$ cholesterol & $\geq 1.30 \mathrm{~g} / \mathrm{l}$ \\
\hline \multicolumn{2}{|c|}{ High plasma triglycerides $\geq 1.19 \mathrm{~g} / \mathrm{l}$} \\
\hline Hyperuricemia & $>57 \mathrm{mg} / \mathrm{l}$ for men and $60 \mathrm{mg} / \mathrm{l}$ for women \\
\hline Dyslipidemia & $\begin{array}{l}\text { LDL cholesterol level } \geq 1.30 \mathrm{~g} / \mathrm{l} \text { and/or HDL cholesterol } \leq 0.4 \mathrm{~g} / \mathrm{l} \text { and/or } \\
\text { total cholesterol levels }>2.8 \mathrm{~g} / 1 \text { and/or triglyceride levels } \geq 1.19 \mathrm{~g} / 1\end{array}$ \\
\hline Renal failure & $\mathrm{GFR}^{*}<90 \mathrm{ml} / \mathrm{min}$ \\
\hline
\end{tabular}

$\mathrm{WHO}=$ World Health Organization; $\mathrm{HDL}=$ hight density lipoprotein; $\mathrm{LDL}=$ low density lipoprotein; GFR = glomerular filtration rate $\mathrm{CVD}=$ cardiovascular disease; $\mathrm{SBP}=$ systolic blood pressure; $\mathrm{DBP}=$ diastolic blood pressure; $\mathrm{BP}$ = blood pressure; $\mathrm{HTA}=$ hypertension. 


\section{Statistical analysis}

The statistical analysis and the data collection were carried out by SPSS 23.0 software. Continuous variables were expressed in mean with standard deviation and categorical variables in number and percentage. The Chi2 test was used to compare the categorical variables. The Student test was used to compare the continuous variables. The odds ratio was calculated for the categorical variables. A level of 5\% was used for the significance of the statistical test.

\section{Results}

We included 100 subjects including 50 patients and 50 controls. The cases were patients followed for SLE in internal medicine department (43 patients or 86\%), nephrology (5 patients or $10 \%$ ), dermatology (2 patients or $4 \%$ ).

We found 44 women (88\%) and 6 men (12\%), the sex ratio H/F was 0.13 in cases. The mean age of patients was $33.5 \pm 11.3$ years. The extremes were 18 and 71 years. More than $3 / 4$ of the patients $(78 \%)$ were less than or equal 40 years old.

The mean duration of lupus was $60 \pm 59.3$ months. The mean diagnostic delay was $30.16 \pm 39.2$ months. The mean activity of the disease was $12.15 \pm 6.8$ at the time of diagnosis and $6.59 \pm 5.6$ at the evaluation.

The majority of patients ( 46 patients, $92 \%$ ) had a treatment by corticosteroids at the time of the evaluation. The mean duration of corticosteroid therapy at the time of the evaluation was $36.46 \pm 53.4$ months with extremes of 0 and 288 months. The mean daily dose of prednisone equivalent was $22.61 \pm 18.9 \mathrm{mg}$ with a minimum of 0 and a maximum of $60 \mathrm{mg}$. The mean cumulative dose was $894.94 \pm 2618.4 \mathrm{mg}$ with extremes of 0 and $1780 \mathrm{mg}$.

Forty-eight (96\%) patients had a treatment by hydroxychloroquine.

For controls, the mean age was $33.3 \pm 11.3$ years without significant difference with cases $(p=0.937)$. The extremes were 18 and 71 years. Also, $78 \%$ of the controls were less than or equal 40 years old.

Diabetes mellitus was found in 2 patients and 1 control, without significant difference $(p=0.157)$. Hypertension and metabolic syndrome were present in as many patients as controls $(\mathrm{p}=1)$. Overweight and obesity were more frequently seen in controls with a significant difference $(p=0.028)$ and the mean body mass index was higher in this population $(p=0.016)$. There was no significant difference in the presence of smoking $(p=0.79)$, sedentary lifestyle $(p=0.307)$, alcoholism $(\mathrm{p}=0.315)$ and obesity $(\mathrm{p}=0.562)$ between cases and controls.

Dyslipidemia was found in 31 cases (63.26\%) and 18 controls (36.7\%) and was significantly associated with SLE $(\mathrm{p}=0.009)$. Similarly, a low HDL cholesterol, noted in 13 cases and 1 control was associated with SLE significantly $(\mathrm{p}=0.001)$. Hypertriglyceridemia was more common in patients $(\mathrm{p}<0.001)$. It was found in 17 cases when no control presented hypertriglyceridemia.

A significant difference between cases $(0.52 \mathrm{~g} / \mathrm{l})$ and controls $(0.61 \mathrm{~g} / \mathrm{l})$ was found for HDL cholesterol level $(\mathrm{p}=0.028)$. The mean level of triglyceride was 
higher in cases $(1.53 \mathrm{~g} / \mathrm{l})$ than controls $(0.62 \mathrm{~g} / \mathrm{l})$, with significant difference $(\mathrm{p}<$ $0.001)$. It was the same for uricemia $(\mathrm{p}<0.001)$ with mean of $62.18 \mathrm{mg} / \mathrm{l}$ in $\mathrm{pa}-$ tients and $46.49 \mathrm{mg} / \mathrm{l}$ in controls.

We didn't found significant difference between cases and controls on high LDL $(p=0.145)$ and total cholesterolemia $(p=0.825)$.

The presence of renal failure $(p=0.043)$ and hyperuricemia $(p<0.001)$ was significantly higher in lupus population.

The summary of the comparison of socio-demographic data and traditional cardiovascular risk factors between cases and controls are presented in Table 2.

Table 2. Comparison of sociodemographic data and traditional cardiovascular risk factors between Cases and Controls.

\begin{tabular}{|c|c|c|c|c|}
\hline & Cases & Controls & p-value & Odds Ratio $[\mathrm{IC}=95 \%]$ \\
\hline \multicolumn{5}{|l|}{ Age } \\
\hline Mean Age & $33.5(11.3)$ & $33.3(11.3)$ & 1 & \\
\hline \multicolumn{5}{|l|}{ Age groups } \\
\hline$\leq 40$ years $(\%)$ & $39(78 \%)$ & $39(78 \%)$ & 1 & \\
\hline$>40$ years $(\%)$ & $11(22 \%)$ & $11(22 \%)$ & 1 & \\
\hline \multicolumn{5}{|l|}{ Gender } \\
\hline Sex ratio $(H / F)$ & 0.13 & 0.13 & 1 & \\
\hline \multicolumn{5}{|l|}{ Division } \\
\hline Women & $44(88 \%)$ & $44(88 \%)$ & 1 & \\
\hline Men & $6(12 \%)$ & $6(12 \%)$ & 1 & \\
\hline Smoking & $3(6 \%)$ & 0 & 0.79 & \\
\hline Sedentary lifestyle & $3(6 \%)$ & $1(2 \%)$ & 0.307 & \\
\hline Alcoholism & $1(2 \%)$ & 0 & 0.315 & \\
\hline early family CVD* & 0 & 0 & NA & \\
\hline Personal CVD* & 0 & 0 & NA & \\
\hline Obesity & $4(8 \%)$ & $6(12 \%)$ & 0.562 & $0.680[0.204-2.264]$ \\
\hline Overweight/obesity & $11(22 \%)$ & $20(40 \%)$ & 0.028 & $0.500[0.262-0.956]$ \\
\hline MS* & $3(6 \%)$ & $3(6 \%)$ & 1 & \\
\hline \multicolumn{5}{|l|}{ Waist size } \\
\hline Mean & 77.53 & 82.38 & 0.114 & \\
\hline Abdominal obesity & $11(22 \%)$ & $22(44 \%)$ & 0.156 & $0.694[0.415-1.160]$ \\
\hline HTA* $^{*}$ & $6(12 \%)$ & $6(12 \%)$ & 1 & \\
\hline Hight $B P^{*}$ & $6(12 \%)$ & $7(14 \%)$ & 0.988 & $1[0.378-2.642]$ \\
\hline Mean SBP* $(\mathrm{mmHg})$ & 118.2 & 110 & 0.233 & \\
\hline Mean $\mathrm{DBP}^{*}(\mathrm{mmHg})$ & 70.6 & 70 & 0.225 & \\
\hline Personal Diabetes & $2(4 \%)$ & $1(2 \%)$ & 0.157 & \\
\hline Fasting blood glucose & & & & \\
\hline
\end{tabular}




\section{Continued}

\begin{tabular}{|c|c|c|c|c|}
\hline Mean (g/l) & 0.76 & 0.85 & 0.000 & \\
\hline Abnormale & $2(4 \%)$ & $1(2 \%)$ & 0.988 & $1.021[0.066-15.856]$ \\
\hline Dyslipidemia & $31(62 \%)$ & $18(36.7 \%)$ & 0.009 & $1.722[1.126-2.634]$ \\
\hline \multicolumn{5}{|l|}{ Total Cholesterol } \\
\hline Mean n (g/l) & 1.97 & 1.98 & 0.954 & \\
\hline High & $14(28.5 \%)$ & $13(26 \%)$ & 0.825 & $1.077[0.566-2.048]$ \\
\hline \multicolumn{5}{|l|}{$\mathrm{HDL}^{*}$-cholesterol } \\
\hline Mean (g/l) & 0.52 & 0.61 & 0.028 & \\
\hline Low & $13(26.53 \%)$ & 1 & 0.001 & $13[1.768-95.582]$ \\
\hline \multicolumn{5}{|l|}{$\mathrm{LDL}^{*}$-cholesterol } \\
\hline Mean (g/l) & 1.1 & 1.3 & 0.103 & \\
\hline High & $15(30.6 \%)$ & $22(44 \%)$ & 0.145 & $0.682[0.404-1.151]$ \\
\hline \multicolumn{5}{|l|}{ Triglycerides } \\
\hline Mean (g/l) & 1.53 & 0.62 & 0.000 & \\
\hline High & $17(34.6 \%)$ & 0 & 0.000 & $0.673[0.554-0.818]$ \\
\hline \multicolumn{5}{|l|}{ Uricémia } \\
\hline Mean (mg/l) & 62.18 & 46.49 & 0.000 & \\
\hline High & $24(48.9 \%)$ & $3(6 \%)$ & 0.000 & $7.486[2.397-23.377]$ \\
\hline Renale failure & $4(8.1 \%)$ & 0 & 0.043 & \\
\hline $\mathrm{GFR}^{*}$ mean $(1 / \mathrm{min})$ & 141.5 & 123.73 & 0.014 & $0.918[0.845-0.998]$ \\
\hline
\end{tabular}

MS = metabolic syndrome; CVD = cardiovascular disease; $\mathrm{SBP}=$ systolic blood pressure; $\mathrm{DBP}=$ diastolic blood pressure; $\mathrm{GFR}=$ glomerular filtration rate; $\mathrm{BP}=$ blood pressure; $\mathrm{BMI}=$ body mass index; $\mathrm{HDL}=\mathrm{high}$ density lipoprotein; LDL = low density lipoprotein; HTA = hypertension; NA = Not apllicable.

\section{Discussion}

The risk of ischemic cardiovascular disease is currently well established during SLE and has emerged as a major cause of mortality after 5 years of progression of the pathology [1] [7] [8] [9] [10]. The increased cardiovascular risk in SLE can be explained by chronic inflammation, the use of corticosteroids, and the high prevalence of traditional risk factors including dyslipidemia and nephropathy [1] [7] [8] [9] [10]. For example, cardiovascular risk assessment in SLE should take into account traditional risk factors and SLE related factors [11]. In this sense, the presence of an early personal or family history of cardiovascular events, diabetes mellitus, a particular personal lifestyle such as smoking, sedentary lifestyle and overweight were considered as important determinants of cardiovascular risk. Biological cardiovascular risk factors were significantly associated with systemic lupus erythematosus in our study.

Many studies show a greater frequency of traditional cardiovascular risk factors in lupus subjects compared to control subjects. Hypertension and dyslipidemia are the predominant factors. High levels of triglycerides and LDL-cholesterol 
and low level of HDL-cholesterol are observed, in addition to HDL dysfunction and excess LDL oxidation [2] [3] [12] [13] [14].

In Africa, although the literature on lupus is increasingly available, studies on cardiovascular risk are rare and are mainly found in North Africa [15].

Our study did not show a significant difference between cases and controls regarding the presence of hypertension, diabetes, smoking, sedentary lifestyle and a history of cardiovascular events. Obesity and overweight were predominant in the control population. In many studies, hypertension was significantly associated with systemic lupus erythematosus [12] [16] [17] [18] [19].

Dyslipidemia was more frequently noted in cases than controls. This dyslipidemia was a type of low HDL cholesterolemia and hypertriglyceridemia. A significant difference was noted between cases and controls on the mean level of HDL cholesterol and triglyceride. Some authors have reported an increase in very low density lipoprotein (VLDL) and triglycerides, but a reduction of HDL in SLE patients, arguing that this profile promotes LDL oxidation and the development of atherosclerosis [2] [3].

Inflammation associated with active disease also leads to dyslipidemia characterized by high levels of cholesterol, VLDL, LDL and triglycerides, thus reducing HDL cholesterol [20].

Among the factors favoring the occurrence of subclinical atherosclerosis during SLE, HDL cholesterol dysfunction is suspected, which acquires inflammatory properties (iHDL) and thus loses its anti-oxidant action on LDL cholesterol [21].

Similar data were reported by Park with significant difference for HDL and triglyceride levels between lupus cases and healthy controls ( $\mathrm{p}$-value $<0.001$ for both variables). Also, this study has revealed a greater fragmentation of lipoproteins possibly responsible for de novo oxidation phenomena [13]. In comparison to our study, the similar results, with the exception of LDL cholesterol, which was significantly higher in patients than in the control population, were reported in a study in Kuwait [14]. These results were contradictory with those of Machado et al. who did not find a significant difference of the dyslipidemia (HDL, LDL, TG, CT) between lupus patients and healthy controls. But they found difference concerning apo lipoproteins. Nevertheless, this study was conducted in a pediatric population (10 - 19 years) [22]. Ahmad et al. found that total cholesterol and high LDL cholesterol levels were associated with SLE [16].

However, the literature data is quite heterogeneous concerning biochemical risk factors. Some studies did not find a significant association between dyslipidemia and SLE [12].

There was a significant difference between patients and controls on the mean value of uricemia and the presence of hyperuricemia $(p=0.000)$. This could be due to renal impairment of SLE. Hyperuricemia is associated with increased cardiovascular risk [23].

The glomerular filtration rate was higher in the patients than in the controls, which could be explained by the possible glomerular hyperfiltration during SLE 
[24]. On the other hand, renal failure was significantly more present in the lupus population than in the control group ( $\mathrm{p}=0.043$ ), this being related to lupus nephritis.

The main limitation of our study was related to the choice of subject controls, some of whom were known for having traditional cardiovascular risk factors. The relatively small sample size constitutes also a limit of this study.

It will be necessary to continue the study by expanding the population, choosing healthy controls and following up patients to screen the occurrence of cardiovascular events.

\section{Conclusion}

In the course of our study, we found a greater incidence of traditional cardiovascular risk factors in lupus patients compared to control subjects. Factors significantly associated with SLE were dyslipidemia, hypertriglyceridemia, low HDL cholesterol, hyperuricemia and renal failure. There was no significant difference regarding LDL cholesterol and hypertension. Obesity and overweight were predominant in the control population.

\section{Conflicts of Interest}

The authors declare no conflicts of interest regarding the publication of this paper.

\section{References}

[1] Tazi Mezalek, Z., Harmouche, H., Ammouri, W., Maamar, M., et al. (2014) Atherosclerosis in Systemic Lupus Erythematosus. La Presse Médicale, 43, 1034-1047. https://doi.org/10.1016/j.lpm.2014.01.021

[2] Liu, Y. and Kaplan, M.J. (2018) Cardiovascular Disease in Systemic Lupus Erythematosus: An Update. Current Opinion in Rheumatology, 30, 441-448. https://doi.org/10.1097/BOR.0000000000000528

[3] Croca, S. and Rahman, A. (2017) Atherosclerosis in Systemic Lupus Erythematosus. Best Practice \& Research Clinical Rheumatology, 31, 364-372. https://doi.org/10.1016/j.berh.2017.09.012

[4] Hochberg, M.C. (1997) Updating the American College of Rheumatology Revised Criteria for the Classification of Systemic Lupus Erythematosus. Arthritis \& Rheumatology, 40, 1725. https://doi.org/10.1002/art.1780400928

[5] Utilisation et interprétation de l'anthropométrie (1995) Rapport d'un Comité d'experts. Organisation mondiale de la Santé, Genève. OMS, Série de Rapports techniques. No 854:367.

[6] Alberti, G. and Zimmet, P. (2006) The IDF Consensus Worldwide Definition of the Metabolic Syndrome. International Diabetes Federation, Bruxelles.

[7] Alenghata, F.J. (2016) The Prevalence of Atherosclerosis in Those with Inflammatory Connective Tissue Disease by Race, Age, and Traditional Risk Factors. Scientific Reports, 6, Article No. 20303. https://doi.org/10.1038/srep20303

[8] Borchers, A.T., Naguwa, S.M., Shoenfeld, Y. and Gershwin, M.E. (2010) The Geoepidemiology of Systemic Lupus Erythematosus. Autoimmunity Reviews, 9, A277-A287. 
https://doi.org/10.1016/j.autrev.2009.12.008

[9] Moya, F.B., Pineda, G.L.F. and García, M. (2016) Impact of Chronic Glucocorticoid Treatment on Cardiovascular Risk Profile in Patients with Systemic Lupus Erythematosus. Journal of Clinical Rheumatology, 22, 8-12. https://doi.org/10.1097/RHU.0000000000000335

[10] Nasonov, E.L., Popkova, T.V. and Novikova, D.S. (2016) Cardiovascular Disease in Rheumatic Diseases. Ter Arkh, 88, 4-12. https://doi.org/10.17116/terarkh20168854-12

[11] Serraj, K., Mecili, M., Zahi, I., Jeandidier, N. and Andres, E. (2011) Connectivites et risque cardiovasculaire: État des lieux. Revue Médecine Thérapeutique, 17, 11-22.

[12] Leeuw, K., Freire, B., Smit, J., et al. (2006) Intima Media Thickness Is Increased in SLE. Lupus, 15, 675-682. https://doi.org/10.1177/0961203306069972

[13] Park, J.K., Kim, J.Y., Moon, J.Y., Ahn, E.T., et al. (2016) Altered Lipoproteins in Patients with Systemic Lupus Erythematosus Are, Associated with Augmented Oxidative Stress: A Potential Role in Atherosclerosis. Arthritis Research \& Therapy, 18, 306. https://doi.org/10.1186/s13075-016-1204-x

[14] Olusi, S.O. and Sunila, G. (2011) Prevalence of LDL Atherogenic Phenotype in Patients with Systemic Lupus Erythematosus. Vascular Health and Risk Management, 7, 75-80. https://doi.org/10.2147/VHRM.S17015

[15] Harzallah, A., Hajji, M., Kaaroud, H., Hamida, B.F. and Abdallah, B.T. (2007) Facteurs de risque cardio-vasculaires au cours du lupus systémique. Pan African Medical Journal, 22, 367. https://doi.org/10.11604/pamj.2015.22.367.7611

[16] Ahmad, Y., Shelmerdine, J., Bodill, H., Lunt, M., et al. (2007) Subclinical Atherosclerosis in Systemic Lupus Erythematosus SLE: The Relative Contribution of Classic Risk Factors and the Lupus Phenotype. Rheumatology, 46, 983-988.

https://doi.org/10.1093/rheumatology/kem002

[17] Lertratanakul, A., Wu, P., Myer, R.D., Kondos, J., et al. (2014) Risk Factors in the Progression of Subclinical Atherosclerosis in Women with Systemic Lupus Erythematosus. Arthritis Care \& Research (Hoboken), 66, 1177-1185. https://doi.org/10.1002/acr.22271

[18] Asanuma, Y., Oeser, A., Shintani, A.K., Turner, E., et al. (2003) Premature Coronary-Artery Atherosclerosis in Systemic Lupus Erythematosus. The New England Journal of Medicine, 349, 2407-2415. https://doi.org/10.1056/NEJMoa035611

[19] Gustafsson, J.T., Lindberg, M.H., Gunnarsson, I., Pettersson, S., et al. (2017) Excess Atherosclerosis in Systemic Lupus Erythematosus: A Matter of Renal Involvement. PLOS ONE, 17, e0174572.

[20] Borba, E.F. and Bonfa, E. (2001) Longterm Beneficial Effect of Chloroquine Diphosphate on Lipoprotein Profile in Lupus Patients with and without Steroid Therapy. Journal of Rheumatology, 28, 780-785.

[21] Volkmann, E.R., Grossman, J.M., Sahakian, L.J., Skaggs, B.J., et al. (2010) Low Physical Activity Is Associated with Proinflammatory High Density Lipoprotein and Increased Subclinical Atherosclerosis in Women with Systemic Lupus Erythematosus. Arthritis Care \& Research (Hoboken), 62, 258-265.

https://doi.org/10.1002/acr.20076

[22] Machado, D., Sarni, R.O.S., Abat, T.T., Silva, S.G.L., et al. (2017) Lipid Profile among Girls with Systemic Lupus Erythematosus. Rheumatology International, 37, 43-48. https://doi.org/10.1007/s00296-015-3393-Z

[23] Allard, A., Bardin, T., Meyer, O., et al. (2009) Hyperuricémie et risque cardiovascu- 
laire. In: Kahn, M.F. and Bardin, T., Eds., L'actualité rhumatologique 2009, Elsevier, Paris, Abstract.

[24] Cottiero, R.A., Madaio, M.P. and Levey, A.S. (1995) Glomerular Filtration Rate and Urinary Albumin Excretion Rate in Systemic Lupus Erythematosus. Nephron, 69, 140-146. https://doi.org/10.1159/000188429 


\section{Appendix}

Data sheet

I) Sociodemographic data

Username

Last name

First name

Age

Gender

Address

Geographic origin

Race/ethnicity

Profession

II) Clinical

\section{A) Antecedents}

\section{Family:}

Early cardiovascular diseases (cardiovascular events, hypertension):

Diabetes mellitus

Personal:

Diabetes mellitus

HTA

Cardiovascular events (stroke, acute coronary syndrome, peripheral arterial disease):

Lifestyle:

Smoking (current or stopped for less than 3 years)

Sedentary lifestyle (lack of physical activity according to WHO)

Alcoholism ( $\geq 3$ glasses/d: man, $\geq 2$ glasses/d: woman)

B) Clinical data:

Lupus duration (months)

Diagnostic delay (beginning of signs-diagnosis)

Activity of the disease at the time of diagnosis

Activity of the disease at the time of evaluation

Blood pressure

Weight

Height

Waist size

Hip circumference

Pulse

III) Biology

Cholesterol:

Total

HDL

LDL

Triglycerides 
Uricemia

Fasting blood glucose

Urea

Serum creatinine level

GFR (MDRD)

IV) Treatment

Corticosteroids:

Duration

Daily dose

Cumulative dose

Hydroxychloroquine

Other treatments:

Statins

Anti-diabetics drugs

Antihypertensive drugs

Others 